\title{
EL DESARROLLO LOCAL EN CONTEXTOS DE GLOBALIZACIÓN Una reflexión desde la experiencia brasileña*
}

\author{
JOSÉ GRAZIANO DA SILVA \\ Universidad Estadual de Campinas. Sao Paulo. Brasil
}

\author{
PALABRAS CLAVE ADICIONALES \\ ADDITIONAL KEYWORDS \\ Latinoamérica, Paises en vía de desarrollo, \\ Latinoamerica, Underdeveloped countries, \\ Desarrollo rural, Sustentabilidad. \\ Rural development, Sustainability.
}

Desde el Instituto de Economía de la Universidad de Campinas (dependiente del gobierno del estado brasileño de Sao Paulo), el Dr. Graziano da Silva se ha caracterizado por haber desarrollado una larga y fructifera carrera académica que, avalada por más de un centenar de publicaciones, le ha hecho merecedor de un justificado prestigio en el ámbito de los estudios rurales latinoamericanos. En su trayectoria académica, el Dr. Graziano da Silva se ha caracterizado por centrar la atención de sus investigaciones en los cambios experimentados por la agricultura y la sociedad rural brasileña. Desde sus primeros trabajos sobre la politica de modernización agricola (modernización "conservadora" en sus propias palabras, por no haber alterado las bases tradicionales de la estructura fundiaria) llevada a cabo por los gobiernos militares de los años 70, ha puesto siempre el énfasis en la necesidad de abordar reformas estructurales que posibiliten el aprovechamiento de las grandes potencialidades de Brasil, un país con una enorme riqueza de

\footnotetext{
* Una versión en inglés de este texto fue presentada como ponencia en el X Congreso Mundial de Sociología Rural, celebrado en Rio de Janeiro (Brasil), entre el 30 de julio y el 3 de agosto de 2000. Agradezco al Dr. Campanhola sus comentarios a la primera versión. La traducción desde el portugués ha sido realizada por Eduardo Moyano.
}

Revista Internacional de Sociología (RIS)

Tercera Época, n 27, Septiembre-Diciembre, 2000, 171-187. 


\section{R IS}

recursos naturales, pèro que, sin embargo, ostenta el titulo de tener una de las tasa más bajas de autosuficiencia alimentaria y de tener que recurrir frecuentemente a las importaciones para garantizar el abastecimiento de la población.

Inicialmente, el Dr: Graziano da Silva centró sus estudios en la "cuestión agraria" y en la necesidad de aplicar una reforma agraria que permitiera reducir la enorme concentración de la tierra en Brasil y favorecer el acceso de una amplia masa de campesinos pobres que hoy son la base del MST (Movimento dos Sem Terra) y que han protagonizado numerosas ocupaciones de haciendas de gran impacto mediático. Su libro O que é Questao Agrária (Sao Paulo, Edit. Brasiliense, 1991), con 18 ediciones, se convirtió en un clásico para toda persona interesada en los problemas del mundo rural brasileño.

No obstante, lo importante del trabajo del Dr: Graziano da Silva, y lo que le diferencia de otros especialistas latinoamericanos en los estudios rurales, radica en el hecho de haberse aproximado al fenómeno de la "cuestión agraria" y de las reivindicaciones campesinas, con una mente abierta a las nuevas corrientes y enfoques teóricos sobre el desarrollo. Tal vez su paso por el Instituto de Estudios Latinoamericanos del University College de Londres en 1990 y su buen conocimiento de las vicisitudes por las que pasó la reforma agraria portuguesa de los años 70 y la inaplicable e inaplicada reforma agraria andaluza de los años 80, han sido factores que han contribuido a la constante renovación de sus concepciones sobre la agricultura y el mundo rural. Esa renovación le ha evitado quedar anclado, como otros, en esas viejas teorias del campesinado que sólo ven la reforma agraria como un mero instrumento de reparto de tierras a los campesinos como compensación por una deuda histórica.

La preocupación del Dr: Graziano da Silva ha sido siempre reflexionar sobre lo que pasaría "el dia después del reparto", es decir, cómo definir proyectos viables de desarrollo para los campesinos asentados, y para ello ha considerado importante conocer las dinámicas sociales y económicas que atraviesan el mundo rural brasileño. En este sentido, sus trabajos más recientes - plasmados principalmente en sus libros A Nova dinâmica da agricultura brasileira (1999) y O Novo Rural Brasileiro (1999) - y el ambicioso proyecto de investigación sobre la sociedad rural de Brasil, que está ahora coordinando en colaboración con investigadores de otras universidades brasileñas, abordan estos temas desde una perspectiva integral y no sólo agrarista (campesina), tratando de desentrañar los elementos fundamentales del proceso de cambio que experimenta el mundo rural. La interacción rural-urbana, la importancia del fenómeno de la pluriactividad, la transformación de los asalariados agrícolas (bóias-frias) en trabajadores rurales, los proyectos de desarrollo local sostenible o la articulación de intereses en los sectores más modernizados de la agricultura brasileña (los llamados complejos agroindustriales), son, entre otros, aspectos esenciales de sus últimos trabajos, que se han plasmado en la dirección de varias tesis doctorales en colaboración con departamentos y centros de investigación europeos (entre ellos, españoles), a los que ha enviado excelentes doctorandos.

Por último destacar; cómo, junto a su actividad académica, el Dr: Graziano da Silva ha desarrollado también una intensa e interesante actividad sindical -como asesor del MST (Movimento dos Sem Terra) y otros sindicatos de trabajadores rurales y pequeños campesinos, como la Contag - y política - como asesor del Partido de los Trabajadores (PT) y del candidato presidencial Luz F. Lula en las dos últimas campañas electorales. Además está encargado del proyecto Fome Zero, cuyo objetivo es proponer una política para la erradicación del hambre en Brasil.

La Revista Internacional de Sociología incluye en su sección de Personalia el texto de la ponencia presentada por el Dr. Graziano da Silva a uno de los simposia organizados en el marco del último Congreso Mundial de Sociología Rural celebrado en el año 2000 en Río de Janeiro. En esta ponencia pueden verse los elementos fundamentales de sus actuales reflexiones sobre los procesos de globalización y sus efectos en el mundo rural, reflexiones realizadas a la luz de una perspectiva comparada Norte-Sur: 


\section{INTRODUCCIÓN}

No es nada nuevo afirmar que la pobreza rural es un serio impedimento para el desarrollo sostenible en los países en vía de desarrollo. Pero, aun reconociendo su gravedad, sería un error pensar que la pobreza es el único problema, ni siquiera el más importante. La falta de vertebración social - especialmente en lo que se refiere a la sociedad civil - se ha constatado como un obstáculo tan grave o incluso mayor que la pobreza de la población rural, ya que contribuye a que ésta se perpetúe. Esto se pone claramente de manifiesto en un momento, como el actual, en que la globalización ha conducido a la revalorización de los espacios locales como arenas de participación social, económica y política para los grupos de intereses organizados.

El nuevo enfoque del desarrollo local sostenible trata estos temas y tiene el mérito innegable de haber ido más allá de las anacrónicas dicotomías urbano/rural y agrario/no agrario. Como sabemos hoy, la actividad agraria se ve profundamente transformada por actividades no agrarias (talleres de maquinaria, empresas de fertilizantes y pesticidas,...), y lo rural no es sólo un espacio definido por su relación concreta con la tierra $-\mathrm{y}$, en términos más amplios, con la naturaleza y el medio ambiente-, sino que está profundamente relacionado con el espacio urbano más próximo.

No obstante, el enfoque del desarrollo local sostenible da por supuesta la existencia de un mínimo de vertebración social en las áreas rurales, que permita a los diversos actores ser los auténticos protagonistas de los procesos que transforman los espacios donde viven. Por ello, considero pertinente no dar eso por supuesto, sino considerar la vertebración social como una condición necesaria para el desarrollo; es decir, entender el desarrollo local sostenible como un proceso de desarrollo político, en el sentido de favorecer una mayor y mejor representación de los diversos actores sociales.

Una cuestión importante a señalar es que, cuando hablamos acerca de estos actores, no debemos referirnos sólo a los agricultores, por muy ampliamente variado que pueda ser este grupo, sino que debemos incluir también a aquellos otros actores que viven en el medio rural o que, desde las áreas urbanas, mantienen una nueva relación con la naturaleza, aunque sólo sea en términos ideales o simbólicos.

Las demandas crecientes de la población en materia de medio ambiente y los problemas relacionados con la gestión y conservación de los recursos naturales, son otros de los factores que han influido en el nuevo protagonismo de los espacios locales. En este sentido, la vertebración de los actores sociales supone un impulso para su participación en la definición y puesta en marcha de los planes de desarrollo local, permitiéndoles orientarlos hacia sus intereses. No obstante, las muchas restricciones que continúan existiendo sobre las formas de participación de los distintos grupos de intereses se deben tanto a los bajos 
niveles de movilización social, como a las dificultades para hacer posible una representación adecuada de todos los sectores implicados en los procesos de desarrollo rural, dada su diversidad A ello habría que anadir la injerencia de las estructuras institucionales existentes en el mundo rural y el poder que en ellas ejercen los grupos dominantes.

En el caso brasileño, por ejemplo, aunque puede decirse que las acciones orientadas exclusivamente hacia el desarrollo agrícola han dado lugar a un alto nivel de modernización de ciertas áreas del país, también es cierto que dicho desarrollo no ha estado acompañado de un proceso paralelo y complementario de desarrollo rural. Una de las principales razones para explicar esta carencia hay que buscarla en el hecho de que sólo han sido atendidos los aspectos tecnológicos y económicos del proceso de desarrollo, posponiendo los cambios sociales y políticos que hubieran sido necesarios para avanzar en la modernización social, tales como el reconocimiento de los derechos laborales y sindicales de los asalariados agrícolas y de los pequeños agricultores. Por ello, no debe extrañar que, con el avance del proceso de globalización, las disparidades que existen hoy en Brasil tiendan a agudizarse, tanto en términos regionales, como en lo que se refiere a la relación entre el sector de la agricultura familiar y el agrobusiness.

\section{LOS EFECTOS DESIGUALES DE LA GLOBALIZACIÓN}

La globalización no es un proceso que tenga lugar con igual intensidad en todos los países, ya que depende del atractivo que éstos puedan ofrecer a las redes internacionales de la nueva economía. Dicho atractivo varía, a su vez, según la importancia económica y política de cada país, el tamaño y potencialidad de su mercado interno, la naturaleza e importancia de las materias primas que interesan a las empresas transnacionales, y la legislación interna que regula las relaciones con el comercio exterior y el flujo de los capitales financieros transnacionales, a los que habría que añadir otros factores como los niveles de corrupción de los gobiernos nacionales (Belo Moreira, 1994). De esta forma, el proceso de globalización no distribuye igualmente sus costes y beneficios entre los diferentes países, ni elimina la necesidad de que intervengan los Estadosnación en aras de la integración nacional. La lógica del proceso globalizador implica una competencia tan brutal y depredadora, así como un grado tan alto de especulación en las inversiones patrimoniales, que sólo puede ser regulada a través de nuevas instituciones y mecanismos de intervención pública que refuercen y complementen los instrumentos de que disponen los gobiernos nacionales.

$\mathrm{Al}$ tiempo que los países se insertan en procesos globales, es un hecho que, dentro de cada país, hay dinámicas que se desarrollan a nivel local para intentar la resolución de problemas que, si bien se manifiestan a ese nivel, sus causas 
hay que buscarlas a niveles más amplios, ya sea dentro o fuera de las fronteras nacionales. En este sentido puede decirse que las fuerzas que actúan en el proceso de globalización son causa de problemas regionales o locales, pero estimulan también dinámicas sociales para intentar darle respuesta en esos niveles inferiores de decisión. Por ello, se hace cada vez más necesario encontrar nuevos modos de equilibrar las interrelaciones que se producen entre los niveles global y local. De ahí que, a la hora de analizar las dinámicas de desarrollo local, no deberíamos limitar nuestro análisis al estricto marco de una comarca o incluso de una región, sino ampliarlo para incluir en él las interacciones entre el nivel local y las dinámicas que acontecen en el proceso de globalización (Campanhola y Graziano da Silva, 2000). La frase «piensa globalmente, actúa localmente», que se ha ido extendiendo para referirse a las estrategias de las regiones y países en un contexto de creciente globalización, tiene especial relevancia en la reflexión que se está haciendo aquí.

La reorganización espacial de la producción implica una aceleración de la movilidad del capital y la creación de filiéres de producción para obtener mayores ventajas competitivas en la acumulación de capital en diferentes países, descentralizando y especializando los procesos de producción. Incluso en los países en vías de desarrollo, la globalización acelera los procesos de exclusión social de los pequeños agricultores, así como de los trabajadores agrícolas y de los consumidores más pobres. Determinadas naciones, regiones y núcleos locales son incorporados a estas filiéres de producción, mientras que otros son excluídos. Así, pues, más que representar un fenómeno mundial de homogeneización en la distribución del capital, el proceso de globalización contribuye a incrementar aún más las diferencias entre naciones y regiones.

En el caso de los sistemas de producción de alimentos, los gobiernos de los países desarrollados procuran no implicarse en ellos mediante sistemas directos de regulación económica, traspasando esa responsabilidad al sector privado. El Estado delega, así, en estos actores intermedios el papel de representar los intereses de los consumidores, concediéndoles determinadas facultades que funcionan tanto a nivel nacional, como más allá de sus fronteras. Así, la supuesta acción de los consumidores a través de las redes de venta al por menor ha contribuido a redefinir los mercados, promoviendo la aparición de nuevos modelos culturales en relación con la calidad nutritiva de los alimentos y con el medio ambiente, tal como ha señalado Marsden (1998). Este autor explica que las redes internacionales de productos alimenticios se conectan horizontal y verticalmente con los espacios donde se localizan, de tal manera que la combinación de esos dos tipos de relaciones ha empezado a remodelar el espacio rural desde dentro, pero de forma interactiva con otros espacios más amplios. De este modo, se crean espacios que actúan en una relación de dependencia y/o de dominación con otros. Por ejemplo, en la industria del vestido, los bienes no se producen en las fábricas que son propiedad de las compañías 
internacionales, sino que su producción es contratada a productores locales, regionales y nacionales, que producen estos bienes (vestido, calzado,...) de acuerdo con las características que les marcan las grandes firmas comerciales (Friedland, 1991). La situación es similar en el caso de la producción de fruta fresca y verdura, que proviene de una amplia gama de núcleos locales, algunos muy lejos de los otros, pero cuya distribución está controlada por compañías transnacionales. Así, los precios de los alimentos están cada vez más determinados en las fases posteriores a la de la producción agraria. De esta forma, y en lo que se refiere a las redes internacionales de productos alimenticios, los procesos de acumulación en el sector de la producción agraria, y más concretamente en la de alimentos, se están diferenciando cada vez más en vez de hacerse más homogéneos; todo lo contrario de lo que inicialmente se podía esperar del proceso de globalización. Es evidente que lo global no puede existir sin lo local, y que lo local se caracteriza por unas relaciones sociales que se ven estructuradas por las relaciones sociales globales (Marsden, 1998).

Es importante subrayar que no todas las actividades productivas locales y regionales están integradas en las redes o cadenas transnacionales. Hay demandas de productos locales y regionales que son también singulares y específicas y que constituyen una importante oportunidad económica para los pequeños y medianos agricultores o incluso para los empresarios agrícolas. La competitividad de cada área o región depende de su habilidad para integrar el saber-hacer local que se ha ido acumulando históricamente y de su capacidad de información e intercambio con los mercados no locales. Por ello, la globalización de los mercados tiene un efecto mayor sobre la diferenciación territorial, que sobre su homogeneización (Saraceno, 1998). Los llamados «nichos de mercados», que se refieren a la demanda de productos con características concretas y alto valor (como, por ejemplo, los alimentos libres de residuos químicos o que no hayan producido daño sobre el medio ambiente en el proceso de producción), están generalmente dirigidos a las clases sociales acomodadas, $\mathrm{y}$, para la población de renta baja, continúa funcionando la demanda de alimentos baratos y escasamente diferenciados que resultan de los procesos de producción en masa.

Junto a estas tendencias, encontramos un cambio importante, favorecido por el proceso de globalización. Me refiero al hecho de que se está produciendo una transferencia del poder y la capacidad política desde un contexto fuerte a nivel nacional, pero débil a nivel local, a otro débil a nivel nacional, pero fuerte a nivel local. Por otra parte, la globalización está estimulando la reestructuración de lo local, en lo que se refiere a las particularidades del uso del espacio y de los actores sociales implicados. La diferenciación y participación en mercados y nichos específicamente localizados ha creado nuevas oportunidades para los pequeños agricultores familiares, cosa que ocurre incluso en países no desarrollados donde estos grupos han sido los menos privilegiados a la hora de afrontar los sucesivos procesos de ajuste macroeconómico (Campanhola y Graziano da Silva, 2000). 


\section{GLOBALIZACIÓN Y EXCLUSIÓN}

De acuerdo con la reflexión que se viene haciendo en este trabajo, puede decirse que el actual proceso de globalización acentúa la naturaleza desigual que ya tenía el desarrollo capitalista en la era fordista, ya que su impacto varía aún más de un país a otro e incluso entre diferentes regiones de un mismo país. Para apoyar esta tesis, destacaré cuatro diferencias fundamentales en lo que se refiere al desigual impacto de la globalización en los países desarrollados — también llamados países del Norte o del Primer Mundo, y a los que me referiré aquí con la abreviatura $\mathrm{Cl}$ - y en los países en vías de desarrollo - también denominados países del Sur, subdesarrollados o de desarrollo tardío, y a los que me referiré con la abreviatura $\mathrm{C} 2$.

\section{Nuevas formas de regulación estatal}

En este aspecto, y en lo que respecta a los países $\mathrm{Cl}$, no sería correcto afirmar que la globalización viene acompañada de una «retirada general del Estado», sino de una reorientación de sus funciones. De hecho, se le demanda funciones de regulación política para nuevas áreas, como ocurre con la interacción entre el medio ambiente y las actividades productivas, por citar un ejemplo de especial interés para el argumento de este artículo. Estas nuevas formas de regulación no son necesariamente públicas, sino que, a menudo, significan una delegación de funciones desde el Estado hacia grupos particulares de intereses a los que se les concede facultades para que ejerzan tareas de control en nombre del interés general, creando así nuevas formas de gobierno privado (Bonano et al., 1994).

En los países C2, la globalización ha tenido lugar dentro de un contexto en el que no sólo se ha reducido la capacidad de los gobiernos nacionales para regular la actividad económica, sino en el que se ha producido una crisis del propio modelo de Estado, tanto en términos fiscales, como en términos de pérdida de su legitimidad social. La crisis fiscal de los Estados-nación en muchos países C2 ha conducido a un verdadero desmantelamiento del sector público en lo que se refiere no sólo a sus funciones de regulación económica, sino también de regulación social. La incapacidad financiera y operativa de los gobiernos nacionales para atender incluso las más mínimas demandas de sus ciudadanos, ha llevado a un escenario de creciente marginalización de grupos sociales que tienen cerrado el acceso a la educación, la salud, el transporte, la vivienda, la seguridad, etc. En los países C2 no se trata simplemente de que el Estado se haya retirado de estas actividades para dedicar más atención a otras nuevas que estén siendo demandadas por la población, como ocurre en los países $\mathrm{C} 1$. Lo que está ocurriendo realmente en los países $\mathrm{C} 2$ es que las instituciones estatales están siendo intencionadamente desmanteladas, condenando a la ruina a las administraciones públicas con el fin de eliminar formas sociales de regulación que se opongan a los objetivos de las compañías transnacionales. 


\section{RIS}

En general, puede decirse que el fenómeno de la retirada del Estado tanto en los países $\mathrm{C} 1$, como en los $\mathrm{C} 2$, no deja «espacios vacíos» para que, de nuevo, la mano invisible (y renovada) del mercado actúe, como a los neo-liberales les gustaría que todos pensemos. A nivel económico, por ejemplo, la bancarrota de los Estados en los países $\mathrm{C} 2$ ha provocado que la función de regular mercados altamente oligopólicos sea asumida por las empresas transnacionales, como se ha puesto de manifiesto en estudios sobre el sector de fruta fresca en Argentina y Chile o en el de zumos concentrados de naranja en Brasil (véanse los trabajos presentados en Cavalcanti, 1999). A nivel social, la retirada del Estado ha hecho que la exclusión se intensifique, contaminando violentamente toda la estructura social y estimulando expresiones radicales de protesta. A nivel político, el vacío dejado por el Estado ha sido ocupado por formas crecientes de autoritarismo por parte de los grupos dominantes, en lo que se refiere a las tareas de regulación privada que le han sido delegadas.

\section{Distintos niveles de vertebración social}

Como hemos visto, en algunas de las nuevas formas de regulación social impulsadas por la globalización, los espacios locales y regionales son cada vez más relevantes. Estas formas de regulación infranacional se originan en el marco de las nuevas relaciones que se establecen entre los sectores públicos y privados, delegando a grupos privados el ejercicio de funciones de gobierno (nuevas formas de gobernancia en la terminología al uso). La diferencia entre los países $\mathrm{C} 1$ y los $\mathrm{C} 2$ en este asunto, es que, en los países $\mathrm{C} 1$, gran parte de la sociedad civil está ya organizada en torno a sus propios grupos de intereses, lo que garantiza su participación en las nuevas formas privadas de gobernancia que se están implantando. Así, en los países $\mathrm{Cl}$ existe al menos la posibilidad de renovar el sistema democrático, en términos de favorecer la representación de los grupos organizados de intereses, contribuyendo a introducir un nuevo equilibrio en la configuración de los Estados-nación. Sin embargo, en los países $\mathrm{C} 2$, en los que la sociedad civil está débilmente organizada, fortalecer los procesos de toma de decisiones a nivel local y/o regional significa en muchos casos revitalizar el poder de los grandes propietarios rurales, ligados por lo general a las élites locales dominantes. En este sentido, y para comprender mejor esta realidad desigual en los países $\mathrm{C} 2$, hay que recordar que la fase más temprana de acumulación fordista nunca fue tan extensa ni tan significativa en estos países, por lo que no dio lugar a la fuerte organización sindical que fue característica de los países $\mathrm{C} 1$ en esa fase. La realidad de los países $\mathrm{C} 2$ está marcada por la existencia de un movimiento obrero débilmente organizado, que convierte a los trabajadores en las principales víctimas de la globalización. De ahí que tenga sentido decir que la muy loada «flexibilización del trabajo» es, en la práctica de los países $\mathrm{C} 2$, una forma ideológica disimulada de retirar del 
movimiento obrero organizado derechos conquistados en épocas precedentes, tal como han mostrado los estudios realizados por Cavalcanti (1999) en Argentina y Brasil.

\section{Nuevos estándares de calidad de vida}

Este tema se suele asociar con el medio ambiente y los alimentos, pero debería extenderse también a las condiciones de trabajo. Como ya se ha planteado, las demandas de los grupos organizados — sobre todo los ecologistas, pero también las asociaciones de consumidores y los sindicatos de trabajadores- se convierten con la globalización en parámetros para medir los nuevos estándares de calidad de vida en los países C1. Las compañías transnacionales utilizan estas demandas como un arma adicional para la competencia, de tal manera que dichos parámetros y estándares de calidad guían las estrategias comerciales de las empresas en todo el mundo. Las normas ISO y sus infinitas versiones no son sino la formalización a escala internacional de estas estrategias.

Desde el punto de vista estrictamente productivo, esto significa imponer restricciones adicionales a todos los sistemas de producción existentes, sean fordistas o no, sean tradicionales o modernos. Concretamente, y en relación con la agricultura, puede decirse que, en los países C2, la aplicación de estas restricciones sobre los sistemas de producción acentúa el carácter excluyente de la competencia entre las empresas capitalistas, eliminando de la cadena productiva los eslabones más débiles, es decir, los que son incapaces de llevar a cabo sistemas de control de la calidad y/o los que se localizan en áreas sujetas a restricciones ambientales.

Esto tiene al menos dos importantes consecuencias para los pequeños agricultores en los países C2. La primera es una concentración cada vez mayor de la producción de bienes que han encontrado un lugar en estas cadenas productivas transnacionales, a lo que habría que añadir el hecho de que son las propias compañías transnacionales las que se encargan de coordinar dichas cadenas - dada la bancarrota del poder público en los países $\mathrm{C} 2$, a la que nos hemos referido más arriba-, acelerando así el proceso de verticalización de la producción agroindustrial. De esta manera, las compañías transnacionales comienzan a dominar también la esfera de la producción agraria en sentido estricto, bien directamente o a través de diferentes mecanismos contractuales (Cavalcanti, 1999).

Una segunda consecuencia está ligada a las restricciones impuestas sobre los agricultores que tienen localizadas sus explotaciones en áreas de interés ecológico, restricciones que, a menudo, debilitan los sistemas de agricultura tradicional existentes en esas áreas. Quizás el caso más extremo que podemos mencionar es el de los campesinos de la región de la Amazonía, que están acostumbrados a técnicas de tala y quema con el objeto de aclarar la tierra para 
R I S

REVISTA INTERNACIONAL DE SOCIOLOGIA

llevar a cabo sus sistemas de agricultura de subsistencia. Las nuevas restricciones ambientales dictadas por grupos organizados de los países $\mathrm{C} 1$ - especialmente, las organizaciones de preservación del medioambiente - acaban por lo general destruyendo la producción local de áreas de los países C2 que han sido puestas en el punto de mira de los intereses ecológicos tal como éstos son definidos por los países $\mathrm{C} 1$.

Además, y más allá de las dificultades que los pequeños agricultores tienen para encontrar un lugar en el actual sistema económico, el proceso de globalización acentúa la exclusión de este grupo y del de los asalariados agrícolas debido a la aceleración que provoca en la dinámica de innovación tecnológica. Las áreas de regadío en los alrededores del río San Francisco en el estado brasileño de Pernambuco ilustran muy bien este asunto. Hace alrededor de diez años, los colonos cultivaban cebolla y tomate en las áreas de riego, creando 6 ó 7 puestos de trabajo anuales por hectárea. Luego, se comenzó a plantar frutales y viñedo, que en esos momentos era un cultivo que requería un uso intensivo de mano de obra y generaba una renta significativa, lo que creó grandes esperanzas respecto a las nuevas oportunidades que el riego - por aspersión o a manta— podía dar a la población caatinga del Nordeste. Hoy, ni la cebolla ni el tomate son rentables, y el viñedo genera sólo 2 puestos de trabajo anuales por hectárea, ya que una nueva técnica de riego (micro-aspersión) desarrollada en Israel se ha introducido en la región, dejando obsoletos miles de kilómetros de canales de hormigón para riego que fueron construidos hace apenas una década a través de fuertes inversiones subvencionadas por el Estado y que aún está pagando el pueblo brasileño. No se trata, por tanto, sólo de la exclusión de los pequeños campesinos que vivían en la región, sino de todos los trabajadores que llegaron allá atraídos por las oportunidades de empleo que traía consigo el sistema de regadío que en aquellos años representaba el no va más en términos de modernización tecnológica de la agricultura del nordeste y que años más tarde quedó obsoleto por la introducción de nuevas tecnologías.

Más allá de estos impactos de la globalización en el nivel productivo, debemos también considerar la fuerte discriminación que se produce sobre los consumidores locales, a los que se les deja para su consumo los productos que no satisfacen los estándares de calidad exigidos para su exportación a los países $\mathrm{C} 1$ o a otras regiones brasileñas con niveles más altos de poder adquisitivo. Éste es un aspecto que no debe ser ignorado: la globalización es también una forma de acelerar las dinámicas de exclusión social dentro de los países C2, tanto en lo que se refiere a los pequeños agricultores, como a los trabajadores y consumidores con menor poder adquisitivo. En este sentido, hay que recordar que, en los países $\mathrm{Cl}$, además de haberse resuelto de un modo general los problemas de satisfacer la demanda interna de alimentos, existen políticas de ayudas y subsidios a los consumidores de menos renta, (en la forma de las pensiones no contributivas, por ejemplo) convirtiéndolos en grupos con poder 
adquisitivo y, por tanto, en potenciales consumidores de alimentos y otros bienes o servicios producidos en sus respectivos países. Esto permite a los gobiernos de los países $\mathrm{Cl}$, al menos parcialmente, compensar la competitividad cada vez menor de sus agricultores en los mercados internacionales, evitando así que las restricciones adicionales ligadas al control de calidad y la protección medioambiental conduzcan a una exclusión social mayor. Puesto que los países C2 carecen de los recursos necesarios para una política social más amplia, son incapaces de romper el círculo vicioso de pobreza-destrucción de los recursos naturales al que están sujetos los pequeños agricultores de las regiones desfavorecidas. Además, puesto que los países $\mathrm{C} 2$ no han solucionado sus problemas de suficiencia alimentaria, es prácticamente imposible que las políticas desincentivadoras de la producción (como el "set-aside" que se aplica en los EE.UU) adquieran legitimidad. En estas regiones, el hambre está asociada no sólo a los bajos niveles de renta, sino también al insuficiente abastecimiento de alimentos básicos, a pesar de la gran capacidad de producción agrícola que tienen los países $\mathrm{C} 2$.

\section{La nueva división internacional del trabajo}

Antes de nada es importante señalar que, en los países C1, la agricultura es hoy un sector económico de cada vez menos importancia desde la perspectiva de la producción, el empleo y la generación de renta. Además, hay que recordar que estos países lograron la autosuficiencia alimentaria en la mayoría de sus productos agrícolas básicos durante la década de los 70 , y que, desde ese momento, su participación en los mercados internacionàles ha tenido lugar como exportadores, a través de los excedentes que genera el sector agrario, o bien como importadores de productos específicos regulados a través de acuerdos bilaterales en los que se fijan los precios y cantidades a negociar. Esto significa que, en el momento en que el proceso de globalización se traslada desde la esfera financiera a la productiva, la dependencia de los países $\mathrm{C} 1$ respecto de los mercados agrícolas internacionales es ya muy baja, y esto es cierto incluso para países, como EE.UU, que exportan una cantidad importante de lo que producen.

Debe señalarse también que los países $\mathrm{Cl}-\mathrm{y}$ esto es particularmente cierto para la Unión Europea, cuya agricultura es menos competitiva que la de los EE.UU - han implantado desde mitad de los años 80 un conjunto de políticas de desarrollo rural, basadas en fuertes incentivos económicos, que no estaban incluidas entre las restricciones que la Ronda Uruguay del GATT impuso sobre las subvenciones agrícolas. Son políticas destinadas a incentivar la reforestación, extensificar la producción agrícola y promover actividades no agrarias en el medio rural - como el turismo rural, la artesanía, las actividades recreativas y de ocio, las de conservación del medio ambiente o preservación del paisaje-, 
RIS

REVISTA INTERNACIONAL IE SOCIOLOGIA

N*27, Septiembre - Diciembre, 2000

JOSÉ GRAZIANO DA SLLVA

que deben ser contempladas como complementos de renta de los agricultores y la población rural en general. Actúan en realidad como compensaciones a los agricultores por la reducción de sus rentas de origen agrícola debida a las restricciones impuestas a las tradicionales políticas proteccionistas basadas en los precios de garantía.

Esto no es sólo un cambio en la orientación de las políticas agrarias de los países $\mathrm{Cl}$, sino que refleja también el hecho de que las políticas de desarrollo rural se impregnan de criterios medioambientales (se hacen más «verdes» en lo que algunos autores denominan the greeening of rural policy) (Moyano y Paniagua, 1998). Como señala Harper (1993), lo que está ocurriendo es que la opinión pública se impregna de valores ambientales (the greening process of the public) y las politicas se ambientalizan (the environmentalization process of the State). Uno de los hechos más ilustrativos de esta tendencia en Europa es la legislación británica sobre «el derecho a pasear por el campo» (right to roam) prometida por la Reina Isabel II en su discurso ante la Cámara de los Comunes el pasado Noviembre de 1999. En esa legislación, se prevé reconocer a los ciudadanos el derecho de acceso a gran parte de la tierra no cultivada, sobre todo en las regiones montañosas de Escocia y País de Gales. Estos nuevos derechos de acceso son también el rasgo principal de la futura ley británica sobre medio ambiente, que prevé establecer una mayor protección de los derechos de los animales salvajes y de los turistas rurales, así como penalizar de un modo más riguroso los delitos ecológicos, tales como coger huevos de nidos de pájaros salvajes. La propuesta está siendo duramente atacada por la asociación de propietarios agrícolas CLA (Country Landwoner's Association), pero apoyada con firmeza por la Rambler's Association (asociación de senderistas), que agrupa a la mayor parte de los grupos ambientalistas y de senderismo.

En el caso de los países C2, el peso económico de la agricultura es, por el contrario, aún muy importante, tanto en términos de creación de puestos de trabajo, como de producción de alimentos, representando una parte significativa de la renta y de los ingresos que estos países necesitan para pagar sus importaciones, unas importaciones que se han incrementado fuertemente como resultado de la globalización. Por ello, el acceso a los mercados agrícolas internacionales es cada vez más importante, tanto para los países que exportan una cantidad significativa de sus productos (como los países integrados en el Grupo Cairns), como para los que han dependido siempre de la importación para hacer frente al déficit de su balanza alimentaria y/o para el control de los precios a nivel interno, como ocurre con Brasil y Argentina. Por otra parte, y dadas las presiones derivadas de los últimos Acuerdos GATT (firmados en Marrakech en 1995), los países $\mathrm{C} 2$ se han visto forzados en estos últimos años a abrir sus mercados a productos agrícolas procedentes del exterior para evitar posibles represalias de los países $\mathrm{Cl}$ que no quieren ver afectadas ni sus exportaciones agrícolas ni las no agrícolas. 
El caso del Nordeste de Brasil es un buen ejemplo de lo que estamos describiendo. Si consideramos sólo las importaciones de la Región Nordeste de Brasil procedentes de los países que forman Mercosul (Argentina, Paraguay y Uruguay, además de Brasil), resulta que se duplicaron entre 1994 y 1996. Estas importaciones están basadas en productos agrícolas, principalmente granos como el trigo y el maíz, lo que ha provocado la casi completa interrupción de los circuitos locales de producción y distribución. El maíz que se consume en la región viene ahora de Argentina, estimulando, por un lado, el desarrollo de una industria avícola moderna en el Nordeste, pero, por otro lado, empeorando las condiciones de vida de los agricultores de las tierras secas del interior, que solían producir maíz en sus pequeñas explotaciones y llevar el excedente a los mercados locales. Además, no sólo se importan inputs, sino también tecnología, como es el caso ya citado de la tecnología del riego por micro-aspersión importada de Israel, o los tipos de tecnología y equipamiento que ahorran trabajo y aceleran el desempleo. El resultado final del proceso de globalización de la agricultura del Nordeste brasileño muestra que la competitividad, antes restringida a niveles locales y regionales, se ha extendido ahora a niveles supra-nacionales e internacionales, acelerando la innovación tecnológica, particularmente en el sector de frutas. Es en el marco de esta loca carrera donde aparecen nuevas formas de gobernancia que conectan el sector público con los intereses privados. Una vez más, los grupos menos privilegiados son los que pierden más con todo este proceso: agricultores pequeños y medianos, asalariados y consumidores con escaso poder adquisitivo.

\section{IMPLICACIONES PARA LAS POLÍTICAS DE DESARROLLO LOCAL}

En la era de la globalización, la idea del desarrollo local ha sido presentada desde hace algún tiempo como la nueva «panacea para el desarrollo económico» en los países del Tercer Mundo. Hoy, a los que vivimos en los países en vía de desarrollo, nos resulta más difícil que antes saber quiénes somos: después de haberse producido lo que, según Schumpeter, podríamos denominar la «destrucción no creativa» del mundo socialista, hemos perdido nuestra identidad como Tercer Mundo y, desde entonces, no hemos vuelto a saber cómo autocalificarnos: si como países de desarrollo reciente, si como países en vía de desarrollo, si como países emergentes o subdesarrollados, o lo que sea.

$\mathrm{El}$ hecho es que todo parece solucionarse aplicando como receta la retirada del Estado, delegando sus poderes de regulación a la sociedad civil organizada a nivel local. La euforia es tal, que hemos olvidado incluso preguntarnos quiénes son exactamente los destinatarios de tales poderes en esa sociedad local supuestamente organizada; qué intereses están representados efectivamente en ella, y cómo se organizan en la realidad. Si lo tuviéramos en cuenta, las respuestas 
serían en la mayoría de los casos muy poco gratificantes. Desafortunadamente, en los países no desarrollados sólo los viejos y oligárquicos intereses están bien representados a nivel local. Los nuevos actores sociales que están surgiendo en el escenario rural de los países $\mathrm{C} 2$ son aún débiles y no han dado lugar a formas institucionalizadas de organización. En ese contexto, las ONGs (organizaciones no gubernamentales) apenas son formas alternativas de organización de intereses. Muchas de ellas son poco más que acuerdos ad hoc dirigidos a conseguir apoyo económico gubernamental e internacional y a emplear a media docena de profesionales plenamente dedicados a su tarea.

No obstante, la idea del desarrollo local no es la primera panacea que se ha intentado vender a los países del Tercer Mundo como «la evolución natural» hacia el desarrollo. Allá por los años sesenta, en los albores de la Revolución Verde, nos autoconvencimos de que el desarrollo agrario llevaría por sí mismo al desarrollo rural. En el caso de Brasil, el resultado fue la «modernización conservadora» de la agricultura, es decir, una modernización sin cambios en la estructura de la propiedad fundiaria, que mantuvo niveles extremadamente altos de concentración de la tierra y de la renta por ella generada, y, por ende, de concentración del poder político a ella asociada. En las áreas rurales brasileñas, ese proceso de modernización conservadora significó la exclusión de los pequeños agricultores, especialmente en áreas que ya eran de por sí pobres. Menos de cincuenta años después de la introducción de nuevas variedades agrícolas cultivadas mediante sistemas altamente mecanizados y gran consumo de productos químicos, Brasil conquistó la envidiable posición de ser uno de los mayores productores de cereales y carne del mundo, así como el mayor exportador de zumo de naranja concentrado y otros logros semejantes. A pesar de ello, una cuarta parte de su población urbana sigue pasando hambre o sufre algún tipo de desnutrición. En el campo, existe un tercio de población rural que está ocupada sólo en actividades no remuneradas o de autoconsumo, y otro tercio está formado por trabajadores ocupados en actividades mal pagadas y sin protección alguna ni por parte de la legislación laboral ni del sistema nacional de salud.

Actualmente, la globalización está acelerando aún más el proceso de exclusión social de los grupos menos favorecidos, acentuando el desequilibrio que ya estaba implícito en la modernización agrícola. Aunque es verdad que la idea del desarrollo local permite superar las viejas dicotomías (rural/urbano y agrario/no agrario), también lo es que, en el mundo rural, no existe un grado suficiente de vertebración social como para garantizar la participación de los nuevos actores sociales en los procesos de globalización.

Es necesario construir una nueva red institucional a nivel local si queremos asegurar que los nuevos sujetos sociales puedan expresarse y exponer sus necesidades. Esta nueva red institucional, que está sólo en fase embrionaria en las áreas rurales de los países subdesarrollados, no debería sólo proponerse como 
una vía para mejorar la representación de los grupos antes excluidos, como los trabajadores sin tierra o los pequeños campesinos, sino que debería también favorecer nuevas formas de representación de los propietarios agrícolas y de los trabajadores asalariados, ambos rehenes de viejas estructuras sindicales unitarias y del predominio de la vieja ideología ruralista. En el caso brasileño, la imposibilidad de permitir una representación plural de los intereses rurales es uno de los factores que contribuyen a la perpetuación del poder en manos de las oligarquías locales, incluso en aquellas regiones en las que éstas no ostentan ya el poder económico o social de antaño'. También debemos buscar vías para representar los intereses de la población que reside en el mundo rural, como los trabajadores no agrícolas, los pensionistas o los residentes de origen urbano propietarios de viviendas en el medio rural o de pequeñas fincas de recreo, así como de aquellos otros grupos que no tienen ningún interés productivo, pero que se preocupan por temas como el paisaje, la preservación de los recursos naturales, la agroecología, etc.

En esta nueva red institucional (Graziano da Silva, 1999), los trabajadores agrícolas y los agricultores no deben monopolizar la representación del mundo rural, ya que los intereses a articular no son ya sólo económicos, ni sectoriales, sino los generales de un espacio delimitado geográficamente y en el que confluyen una diversidad de actores sociales. En muchos casos, por ejemplo, el ámbito local debería ser más amplio que el de un municipio, extendiéndose a ámbitos como el de una región o una cuenca hidrográfica, una zona de montaña o incluso un área que produzca cierto producto en torno al cual giren los intereses de distintas localidades, como ocurre con la región del cacao de Bahía o de la caña de azúcar en el Nordeste.

Un tema fundamental es cómo construir esa nueva red institucional: ¿comenzando a partir de las estructuras y organizaciones ya existentes, o a partir de nuevas identidades?. En principio, parece que no hay una regla clara sobre si excluir una u otra de estas posibilidades. Así, parece obvio que las instituciones dedicadas a la enseñanza, investigación y asistencia técnica tendrían que ser reformuladas para incluir las dimensiones no agrícolas del desarrollo rural/local. Por otra parte, parece también lógico que tal reformulación no puede llevarse a cabo simplemente agregando nuevos departamentos, secretariados o incluso ministerios a los ya existentes, que, no lo olvidemos, fueron creados en los

\footnotetext{
' La normativa sobre el sindicalismo democrático es una de las pocas disposiciones transitorias de la Constitución de 1988, que no ha sido regulada aún, manteniéndose, por tanto, las viejas instituciones (como la Contag y la CNA) creadas durante la dictadura militar e inspiradas en la legislación corporativista que estaba en boga en los años 30 en Europa (Graziano da Silva, 1999).
} 
albores de la Revolución Verde de los años sesenta y están por ello impregnados de la lógica que le acompañó. Por encima de todo, se debe modificar el contenido, los métodos y los objetivos de estos organismos, así como de sus programas y métodos de actuación. Igualmente, habría que reconocer que las políticas de descentralización administrativa y económica no son suficientes por sí solas para fortalecer el poder de los nuevos actores sociales que están emergiendo, sino que se necesita crear nuevos mecanismos para facilitar la participación de las poblaciones locales, mecanismos que deben ir más allá de la creación formal de - «consejos de desarrollo» donde los actores sociales sólo tienen posibilidad de expresar sus opiniones sobre el destino de los fondos transferidos a los gobiernos locales (Campanhola y Graziano da Silva, 2000). Mas hasta ahora, el tema de cómo crear una nueva red institucional a nivel local, es una cuestión aún abierta, que no puede resolverse "ex-ante" como dicen los economistas, sino en la práctica: es decir, planteando soluciones a medida que se va luchando por la transformación de la estructura de poder en cada localidad.

\section{BIBLIOGRAFÍA}

BELO MOREIRA, M. (1994), "The firm and the state in the globalization process", International Journal of Sociology of Agriculture and Food, Lisboa, vol. 4, pp. 84-112, Portugal.

BONANNO, A. et al. (1994), From Columbus to Conagra: the globalization of food and agriculture, University of Kansas Press, Lawrence, USA.

CAMPANHOLA, C. y J. GRAZIANO DA SILVA (2000), "Local Development and Democratization of Rural Territory", comunicación presentada al X Congreso Mundial de Sociología Rural, Rio de Janeiro, Brasil, julio-agosto.

CAVALCANTI, J. S. B. (coord.) (1999), Globalização, trabalho, meio ambiente: mudanças socioeconômicas em regiões frutícolas para exportação, Recife, Editora Universitaria de la UFPE, Brasil.

HARPER, S. (ed.) (1993), The greening of Rural Policy: International Perspectives, Belhaven Press, Londres, Reino Unido.

FRIEDLAND, W. et al. (eds.) (1991), Towards a New Political Economy of Agriculture, Boulder, Westview Press, USA.

GRAZIANO DA SILVA, J. (1993), "Las organizaciones profesionales en la moderna agricultura brasileña", Agricultura y Sociedad, n $68-69$, julio-diciembre, pp.195-217, MAPA, Madrid.

(1999), O novo rural brasileiro, Campinas, Instituto de Economia-Unicamp, Coleção Pesquisa, $n^{\circ} 1$, Brasil.

MARSDEN, T. (1998), "New rural territories: regulating the differentiated rural spaces", Journal of Rural Studies, vol. 14, $\mathrm{n}^{\circ}$ 1, pp.107-117, Reino Unido. 
MOYANO, E. y A. PANIAGUA (1998), "Agricultura, espacios rurales y medio ambiente", Revista Internacional de Sociologia, n'.19-20, pp.127-152, CSIC, Madrid, España.

SARACENO, E. (1998), "Urban-rural linkages, internal diversification and external integration: a European experience”, Políticas Agricolas, número monográfico, pp. 71-104, 1998, Brasil.

E-mail: graziano@eco.unicamp.br 